\title{
KOSMOLOGI DALAM TAFSIR AL-IBRIZ KARYA BISRI MUSTAFA: RELASI TUHAN, ALAM DAN MANUSIA
}

\author{
Mahbub Ghozali \\ UIN Sunan Kalijaga Yogyakarta \\ mahbub.ghozali@uin-suka.ac.id
}

Diterima 06-03-2020 | Direview 02-04-2020 | Diterbitkan 27-06-2020

\begin{abstract}
Cosmology in Javanese perspevtive has big implications to directing the whole concept of its action. This concept animates in every Javanese perception and action when viewing the world, including in the area of interpretation of the Qur'an. One book that consistently presents its identity as a Javanese exegesis is al-Ibriz by Bisri Mustafa. On that basis, this study aims to find the concept of cosmology in the interpretation of al-Ibriz. Based on this aims, this research uses descriptive analysis method with the type of literature study. This study also uses data analysis techniques using the hermeneutics method by Hans-Goerg Gadamer. This study found that the relationship between God, nature and bumans in the interpretation of al-Ibriz depicted from buman actions in the real world. Humans as the center of the real world, have an obligation to maintain and use the world as possible. As a consequence of this, bumans must constantly carry out worship to God and maintain relationships with other humans. The action is an attempt to maintain the balance and peace of their lives in the real world which also has implications in the afterlife
\end{abstract}

Keywords: Cosmology, Bisri Mustafa, al-Ibriz, Javanese Philosophy, Unity

\begin{abstract}
Abstrak
Kosmologi dalam pandangan Jawa memiliki implikasi yang besar dalam mengarabkan selurub konsep tindakannya di dunia. Konsep ini menjiwai dalam setiap persepsi dan tindakan orang Jawa dalam memandang dunia, termasuk. dalam wilayah penafsiran terhadap al-Qur'an. Salab satu tafsir yang secara konsisten menampilkan identitasnya sebagai tafsir Jawa adalab al-Ibriz karya Bisri Mustafa. Atas dasar itu, penelitian ini bertujuan untuk menemukan konsep kosmologi dalam tafsir al-Ibriz. Untuk mencapai tujuan tersebut, penelitian ini menggunakan menggunakan metode diskriptif analisis dengan jenis penelitian studi pustaka. Penelitian ini juga menggunakan teknik analisa data dengan menggunakan metode hermeneutika Hans-Goerg Gadamer. Dari hasil pembahasan, penelitian ini menemukan bahwa relasi antara Tuban, alam dan
\end{abstract}


manusia dalam tafsir al-Ibriz tergambar dari tindakan manusia di dunia nyata. Manusia sebagai pusat dari dunia nyata, memiliki kewajiban untuk menjaga dan memanfaatkan dunia sebaik mungkin. Konsekuensi dari hal tersebut, manusia harus senantiasi menjalankan ibadah kepada Tuban dan menjaga bubungannya dengan manusia yang lain. Tindakan tersebut sebagai upaya untuk menjaga keseimbangan dan ketentraman kehidupan mereka di dunia nyata yang juga memiliki implikasi di kehiduap akhirat.

Kata Kunci :Kosmologi, Bisri Mustafa, al-Ibriz, Filsafat Jawa, Manunggaling

\section{Pendahuluan}

Jawa dengan segala bentuk pandangannya terhadap dunia (worldview) telah banyak menarik perhatian para peneliti. Banyak diantara mereka mendalami konsep-konsep yang dimiliki oleh masyarakat Jawa dalam menjalani kehidupannya. Denys Lombard pernah melakukan penelitian untuk mencari alasan dibalik kepatuhan masyarakat Jawa terhadap raja-raja mereka. Dalam kesimpulannya, Lombard mengungkapkan bahwa kepatuhan mereka terhadap Raja dipengaruhi keyakinan atas fungsi Raja sebagai penyeimbang antara mikrokosmos dengan makrokosmos. ${ }^{1}$ Dalam konteks yang sama, Mark R. Woodward juga berkesimpulan bahwa ketaatan masyarakat Jawa terhadap Rajanya dipengaruhi oleh pandangan mereka tentang kosmologi. ${ }^{2}$

Pandangan masyarakat Jawa mengenai kosmos yang didalamnya memuat relasi Tuhan dan alam, terjalin semenjak lama. Bahkan, jika konsep ini ditarik lebih jauh lagi, aktivitas yang dilakukan mereka selalu bergantung pada kekuatan-kekuatan alam yang diyakini sebagai bagian dari tanda-tanda yang diberikan oleh Tuhan. Alam selalu diasosiasikan sebagai sesuatu yang hidup dan memberikan kehidupan. Dalam piwnlang Kawruh Kejawen, terdapat tiga konsep keyakinan masyarakat Jawa mengenai hubungan manusia, Tuhan dan alam. Pertama, konsep mengenai Tuhan sebagai penjaga Alam (kang murbeng alam). Kedua, kesadaran akan wujudnya alam. Ketiga, keadaran atas eksistensi manusia yang harus dijaga pola hubungannya. ${ }^{3}$

Seluruh konsep keseimbangan antara makrokosmos dan mikrokosmos menjiwai segala tindakan yang dilakukan dalam menjalani kehidupan mereka. Bahkan, konsep ini telah menjadi bagian dari konsep diri masyarakat Jawa

\footnotetext{
${ }^{1}$ Denys Lombard, Nusa Jawa: Silang Budaya (Jakarta: Gramedia Pustaka Utama, 2005).

2 Mark R. Woodward, Islam Jawa: Kesalehan Normatif versus Kebatinan, trans. Hairus Salim (Yogyakarta: LKiS, 2004).

3 Janmo Dumadi, Mikul Dhunur Mendhem Jero: Menyelami Falsafab Dan Kosmologi Jawa (Yogyakarta: Shaida, 2011).
} 
secara turun temurun. Implementasi tersebut pada akhirnya menciptakan satu konsep baru dalam filsafat Jawa yang disebut dengan etika Jawa. ${ }^{4}$ Konsep ini tidak hanya berhubungan dengan tindakan-tindakan manusia Jawa dalam kaitannya menjaga relasi antara sesama manusia, akan tetapi juga menyangkut pada konsep-konsep magis-teologis yang berkaitan dengan relasi mereka dengan Tuhan. ${ }^{5}$ Bahkan, Benedic R. Anderson menyebutkan praktik keyakinan Jawa tentang kosmologi ini sebagai bagian dari watak orang Jawa yang tidak bisa dengan mudah dihilangkan. ${ }^{6}$ Dengan penyebutan sebagai bagian dari watak, maka pola pikir masyarakat Jawa dapat dipastikan memiliki corak tentang konsep-konsep tersebut. Hal ini juga berpengaruh dalam konsepkonsep yang ditawarkan dalam setiap pemikiran keagamaan, termasuk dalam tafsir.

Tafsir sebagai saran untuk memberikan penjelasan mengenai makna dan tujuan hukum dalam ayat al-Qur'an, ${ }^{7}$ memungkinkannya untuk terbuka terhadap pembacaan yang dilakukan oleh sang penafsir dengan background keilmuan dan sosial-kultur yang membentuknya. ${ }^{8}$ Pendekatan yang digunakan oleh penafsir sesuai dengan apa yang dimilikinya membentuk kecenderungan dalam hasil penafsiran. Dalam kajian tafsir kecenderungan ini dikenal dengan sebutan ittijahat (corak), sehingga memungkinkan terdapat warna yang berbeda dalam setiap tafsir sesuai dengan pendekatan yang digunakan oleh orang yang menafsirkan. ${ }^{9}$ Dalam pandangan Hans-George Gadamer, setiap pembacaan terhadap teks, akan selalu melibatkan dealektika antara teks dengan kecenderungan (pre-judice) penafsir yang dipengaruhi oleh konsepsi mereka tentang dunia. ${ }^{10}$

Keniscayaan ini juga terjadi ketika Bisri Mustafa sebagai bagian dari masyarakat Jawa mendekati al-Qur'an dengan membawa konsep-konsepnya

\footnotetext{
${ }^{4}$ Hildred Geertz, Keluarga Jawa (Jakarta: Grafiti Press, 1961), 38.

${ }^{5}$ P. M. Laksono, Tradisi Dalam Struktur Masyarakat Jawa Kerajaan Dan Pedesaan: Alih Ubah Model Berpikir Jawa (Yogyakarta: KEPEL Press, 2009), 14.

${ }^{6}$ Benedic B. Anderson, Mitologi Dan Toleransi Orang Jawa, trans. Revianto B. Santoso and Luthfi Wulandari (Yogyakarta: Qalam, 2000), 1.

7 Muhammad bin Abd Allah Al-Zarkasyi, Al-Burhan Fi 'Ulum al-Qur'an, vol. 2 (Beirut: Dar Ih ya' al-Kutub al-'Arabiyah, 1957), 148-49.

${ }^{8}$ Nasr Hamid Abu Zayd, Tekstualitas Al-Qur'an: Kritik Terhadap Ulumul Qur'an, trans. Khoiron Nahdliyyin (Yogyakarta: LKiS, 2013), 325-26.

9 Fu'ad Abd al-Rahman Al-Rumi, Ittijahat Al-Tafsir Fi al-Qarn al-Rabi' 'Ashr, vol. 1 (Riyad: Mu'assasah al-Risalah, 1997), 9.

${ }^{10}$ Hans-Georg Gadamer, Truth and Method, trans. Joel Weinsheimer and Donald G. Marshall (London: Continuum, 2006), 6.
} 
mengenai tradisi dan budaya Jawa yang membentuknya. Argumentasi yang dapat menguatkan pandangan ini adalah tujuan penulisan kitab ini yang didasarkan pada penyebaran kandungan al-Qur'an kepada masyarakat Jawa yang tidak mengerti bahasa Arab. ${ }^{11}$ Kecenderungan Bisri Mustafa terhadap konteks ke-Jawaannya juga dapat dilihat dari penggunaan bahasa Jawa dalam menjelaskan ayat-ayat al-Qur'an dalam Tafsir al-Ibri \% . Keterpengaruhan Bisri Mustafa terkait tradisi kejawaan juga dijelaskan dalam penelitian Idrus alHamid dengan judul Eksistensi Kebudayaan Jawa dalam Penafsiran KH Bisri Mustafa. Al-Hamid menjelaskan beberapa konsep etika Jawa dalam Tafsir alIbri $>$ ₹, seperti konsep religius-magis dan kawula-Pangeran. ${ }^{12}$

Keterpengaruhan Bisri Mustafa dalam melakukan penafsiran terhadap ayat-ayat al-Qur'an tidak hanya didasarkan pada tradisi dan budaya Jawa, akan tetapi juga dipengaruhi oleh kontek tradisi pesantren yang juga merupakan background budaya yang membentuknya. Hal ini dibuktikan oleh Muhammad Asif dalam penelitiannya yang berjudul Qur'anic Exegesis and The Tradition of The Pesantren: Characteristics of Tafsir al-Ibriz of Bisri Mustafa. ${ }^{13}$ Penelitian lain yang terkait dengan al-Ibriz adalah penelitian yang dilakukan oleh Aunillah Reza Pratama dengan judul Women Rights in Qur'anic Exegesis of al-Ibriz, and Ta>j alMuslimi $>n$. Penelitian ini menyimpulkan bahwa Bisri Mustafa menempatkan penafsiran atas hak-hak wanita di bawah konsepsi Patriarkal yang mejadi ciri khas dari budaya Jawa. ${ }^{14}$

Meskipun banyak penelitian berusaha mengungkap pertautan antara tradisi Jawa dalam penafsiran yang dilakukan Bisri, akan tetapi konsep utama dalam tradisi Jawa tidak pernah disunggung. Hal yang menjadi ciri khas dari pandangan dunia Jawa adalah terkait dengan kasatuan pandangan teradap realitas yang dibentuk oleh relasi manusia, alam, dan Tuhan. Dalam konteks ini, Franz Magnis-Suseno menganggap bahwa konsep utama dalam pemikiran Jawa

\footnotetext{
11 Bisri Mustofa, Al-Ibriz: Tafsir al-Qur'an Bahasa Jawa (Wonosobo: Lembaga Kajian Strategis Indonesia, 2015), iv.

12 Idrus al Hamid, "Eksistensi Kebudayaan Jawa Dalam Penafsiran KH. Bisri Mustafa," Mutawatir: Jurnal Keilmuan Tafsir Hadith 9, no. 1 (2019).

${ }^{13}$ Muhammad Asif, "Qur'anic Exegesis and The Tradition of The Pesantren: Characteristics of Tafsir al-Ibriz of Bisri Mustafa," SUHUF Jurnal Pengkajian Al-Qur'an Dan Budaya 9, no. 2 (2016): 241-64, https://doi.org/10.22548/SHF.V9I2.154.

14 Aunillah Reza Pratama, "HAK-HAK PEREMPUAN DALAM TAFSIR AL-IBRĪZ DAN TAFSIR TĀJ AL-MUSLIMĪN," SUHUF Jurnal Pengkajian Al-Qur'an Dan Budaya 11, no. 2 (December 31, 2018): 283-308, https://doi.org/10.22548/SHF.V11I2.359.
} 
terakumulasi dalam konsep religiusnya mengenai kosmologi. ${ }^{15}$ Atas dasar tersebut, penelitian ini bertujuan untuk menemukan konsep kosmologi Jawa dalam penafsiran Bisri Mustafa di Tafsir al-Ibriz:

Untuk mencapai tujuan tersebut, penelitian ini menggunakan metode diskriptif analisis dengan jenis penelitian studi pustaka. Penelitian ini juga menggunakan teknik analisa data dengan menggunakan metode hermeneutika Hans-Goerg Gadamer. Sumber data sebagai bahan dasar dalam penelitian ini, adalah Tafsir al-Ibriz, fi Ma'rifah Tafsir al-Qur'an al-Aziz karya Bisri Mustofa. Selain itu, penulis juga merujuk pada beberapa literatur kajian terdahulu yang telah disebut sebagai bahan rujukan pendukung.

\section{Metode}

penelitian ini menggunakan menggunakan metode diskriptif analisis dengan jenis penelitian studi pustaka. Penelitian ini juga menggunakan teknik analisa data dengan menggunakan metode hermeneutika Hans-Goerg Gadamer.

\section{Kosmologi Jawa: Memahami Relasi Manusia, Alam, dan Tuhan}

Istilah Kosmos pertama kali dikenal dalam beberapa tulisan karya filosuf Yunani, seperti Pythagoras dan Plato. Akan tetapi, penggunaan istilah ini tidak merujuk pada definisi khusus yang dipahami sebagai kajian mengenai alam. ${ }^{16}$ Justru, istilah yang digunakan untuk menunjukkan ilmu tentang alam dikenal pada masa skolastik Yunani dengan istilah philosophia nature atau dalam karya-karya Aristoteles disebut dengan fusika ${ }^{17}$ Kosmologi sebagai disiplin ilmu mandiri baru diperkenalkan oleh Christian Wollf sebagai bagian dari cabang ilmu metafisika. Wolff meletakkan dasar pembahasan kosmologi pada segala sesuatu tentang ada. ${ }^{18}$

Kosmologi sebagai bagian dari ilmu metafisika, menjadikan keilmuan ini mengacu pada eksistensi diluar dunia materi. Hal ini terjadi karena potensi akal yang dimiliki manusia ketika mengahadapi realitas, selalu berkembang hingga mencapai keraguan atas eksistensi dirinya, kehidupan dan masa

\footnotetext{
${ }^{15}$ Franz Magnis-Suseno, Etika Jawa: Sebuah Analisis Falsafati Tentang Kebijaksanaan Hidup Jawa (Jakarta: Gramedia, 1984), 82-83.

16 Anton Bekker, Kosmologi Dan Ekologi: Filsafat Tentang Kosmos Sebagai Rumah Tangga Manusia (Yogyakarta: Kanisius, 1995), 27.

${ }^{17}$ Bekker, 40.

18 Maria R. Antognazza, “Arguments for The Existence of God: The Continental European Debate," in The Cambridge History of Eighteenth-Century, ed. Knud Haakonssen, vol. 1 (New York: Cambridge University Press, 2006), 741.
} 
depannya. Pada titik ini, seseorang akan mulai mempertanyakan konsep-konsep dasar mengenai kehidupnya, hingga ia dapat merasakan kehadiran alam semesta dalam dirinya. ${ }^{19}$ Untuk mencapai tingkatan ini, maka diperlukan penyatuan seluruh konsep keilmuan dalam satu perspektif, sehingga banyak kalangan menganggap kosmologi sebagai bagian keilmuan yang rumit dalam filsafat.

Dalam konteks ini, Anton Bekker membagi kajian dalam kosmologi menjadi dua, kosmologi filsafat dan kosmologi empirik. Dalam pembahasan kosmologi filsafat, konsep dasar mengenai kosmologi diberiakan penjabaran lebih mendetail untuk memberikan pemahaman yang mendelam mengenai relasi-relasi kosmos, serta kosep-konsep penting didalamnya. Sedangkan kosmologi empirik mencakup langkah kongkrit mengenai pemahaman kosmologi yang masih umum, sehingga pemahaman fundamental dalam kosmologi filsafat memberikan perspektif bagi pengetahuan empiris yang lebih khusus..$^{20}$ Secara lebih praksis, Bekker menjelaskan mengenai hubungan antara manusia dan alam dalam konsep kosmologi, dengan penjelesan bahwa manusia menyadiri eksistensi dirinya di dunia dengan kesadaran khusus. Kesadaran ini memungkinkan bagi manusia merasakan relasinya dengan manusia yang lain di dalam dunia yang lebih luas, sehingga kesadaran manusia terhadap dunia tercapai ketika ia merasakan hubungan dengan manusia yang lain. Pemahaman semacam ini disebut Bekker sebagai kesatuan objektif. Kesadaran manusia terhadap dunia menurut Bekker juga dapat dicapai dengan cara yang formal. Manusia mencari eksistensi dunia, dengan jalan mempertanyakan dunianya. Dengan kemampuan untuk menemukan jawaban-jawaban atas pertanyaan tersebut, keberadaan manusia dapat dibedakan dengan makhluk lainnya yang hanya memperlakukan dunia sebagai tempat mereka hidup. ${ }^{21}$

Kesadaran formal mengenai dunia, tidak berlangsung seketika. Ia membutukan proses yang panjang, sehingga manusia benar-benar menyadari eksistensi dunianya. Dalam hal ini Cornelis A. van Peursen membagi proses tersebut ke dalam tiga tahap. Pertama, tahap mitologis, yakni kesadaran mengenai eksistensi alam yang diperoleh dengan asosiasi-asiosiasi kekuatan supranatural yang dimiliki oleh alam. Kedua, tahap ontologis, yakni manusia mulai sadar bahwa gerak alam tidak didasarkan pada kekuatan-kekuatan mistis, akan tetapi terdapat alasan yang logis mengenai hal tersebut. Ketiga, tahap

\footnotetext{
${ }^{19}$ Archie J. Bahm, Metaphysics: An Introduction (New Mexico: Harper \& Row, 1986), 6.

${ }^{20}$ Bekker, Kosmologi Dan Ekologi: Filsafat Tentang Kosmos Sebagai Rumah Tangga Manusia, 56.

${ }^{21}$ Bekker, 29.
} 
fungsional, yakni kondisi kesadaran yang dimiliki oleh manusia mengenai potensi alam yang dapat digunakan untuk kepentingan mereka. ${ }^{22}$

Dalam konteks masyarakat Jawa, kesadaran mereka tentang dunia terimplementasikan dalam setiap tindakannya. Mereka menyadari atas eksistensi dunia dengan menciptakan relasi dengan manusia lainnya. Oleh sebab itu, mayoritas orang Jawa berusaha mempertahankan hubungan dengan sikap yang tepo seliro, ramah dan etika-etika lainnya. Bahkan, dalam pandangan masyarakat Jawa kuno, kesadaran tentang eksistensi alam berada pada dimensi mistis yang selalu menggap alam mengatur segala bentuk aktivitas manusia dengan petanda-petanda khsusus. Sikap ini yang menjadikan masyarakat Jawa sebagai komunitas yang penuh dengan mistifikasi, mitologisasi dan sakralisasi.

Mistifikasi alam dalam persepsi masyarakat Jawa dapat dilihat dari keyakinannya mengenai kehidupan dan penghidupan dari alam. Dalam Piwulang Kawruh Kejawen, terdapat beberapa ajaran yang dipengang teguh oleh mayoritas orang Jawa. Ajaran ini menyangkut keyakinan terhadap Tuhan, keyakinan atas eksistensi alam, dan keyakinan untuk tetap menjaga hubungan sesama manusia. ${ }^{23}$ Tiga keyakinan ini merupakan konsep kosmologis dalam pandangan Jawa. Makrokosmos diwakili dengan pandangan atas kekuatan-kekuatan magis yang dimiliki oleh alam. Alam dalam pandangan Jawa tersusun dari beberapa tingkatan yang sifatnya hirarkis. Alam juga tersusun dari lima unsur yang terdiri dari empat arah dan satu pusat. Pusat tersebut sebagai unsur yang paling penting karena bertugas menjaga keseimbangan dan mempersatukan. ${ }^{24}$

Sedangkan mikrokosmos dipahami sebagai bentuk praksis atas kesadaran mengenai dunia nyata. Mikrokosmos terdiri atas segala struktur sosial yang ada dalam masyarakat yang mencakup segala eksisten yang dapat di indera. Dalam tatanan mikrokosmos, keraton diletakkan sebagai pusat segalanya yang bertugas menjaga keseimbangan di dunia nyata. Sementara itu, Raja yang merupakan penguasa kraton berfungsi sebagai penyeimbang dan menjaga keserasian antara makrokosmos dengan mikrokosmos. Raja dipandang memiliki kekuatan-kekuatan kosmis yang dapat mengalirkannya ke daerah, sehingga dapat membawa kemakmuran, ketentraman dan kesuburan. ${ }^{25}$

\footnotetext{
${ }^{22}$ Cornelis A. Van Peursen, Strategi Kebudayaan (Yogyakarta: Kanisius, 1988), 18.

23 Janmo Dumadi, Mikul Dhuwur Mendhem Jero: Menyelami Falsafah Dan Kosmologi Jawa (Yogyakarta: Shaida, 2011), 30-31.

${ }^{24}$ Denys Lombard, Nusa Jawa: Silang Budaya, trans. Winarsih Partaningrat Arifin and Rahayu S. Hidayat (Jakarta: Gramedia Pustaka Utama, 2005), 100.

${ }^{25}$ Lombard, 60.
} 
Cara pandang terhadap dunia yang demikian terjaga dari generasi ke generasi. Hal ini disebabkan karena pandangan orang Jawa terhadap dunia, terintegrasi kedalam keyakinan mereka dalam beragama. Hal yang paling sederhana untuk menjelaskan ini adalah kebiasaan mereka untuk mempersembahkan makanan kepada sesuatu yang dianggap memiliki kekuatan mistis. Kebiasaan ini pada dasarnya meruapan konsep-konsep pemahaman atas kosmos yang diidentikkan dalam ritual agama. Praktik lainnya adalah kebiasaan Jawa yang melakukan aktivitas sehari-hari yang masih dikaitkan dengan keadaan alam atau bahkan waktu kelahiran seseorang (weton). ${ }^{26}$ Bahkan, dalam pandangan Woodward, konsep ini merupakan konsep utama dalam kehidupan politik, hubungan sosial hirarkis, dan kesatuan mistik masyarakat Jawa. ${ }^{27}$

Kesatuan mistik dalam konsep ini sangat jelas tergambar dalam konsepkonsep relasi hubungan manusia dengan Tuhan yang disebut dengan manunggaling kawula-Gusti. Hubungan kesatuan ini disebutkan dengan banyak istilah lain, diantaranya sabawa rasa manunggaling kawula Lan Gusti, pamoring kawula-Gusti, jumbuhing kawula-Gusti, curiga manjing warangka, dan warangka manjing curiga. Istilah tersebut menunjukkan pada makna yang sama, yakni kesatuan antara dua unsur yang berlawanan. Akan tetapi, konsep ini pada dasarnya bukan untuk menunjukkan satu ajarah tertentu yang dilekatkan pada Syekh Siti Jennar, akan tetapi istilah ini menunjukkan satu pengalaman khusus yang dirasakan oleh seseorang dalam proses pencariannya terhadap dunia. ${ }^{28}$ Pengalaman semacam ini hanya bisa dirasakan oleh beberapa orang tertentu, tanpa bisa di diskripsikan secara konkret. Kesadaran manusia dengan Tuhan memiliki sifat yang berbeda dengan kesadarannya tentang alam. Tuhan dalam pandangan Jawa dipahami sebagai perkara yang tidak dapat dilihat, akan tetapi dapat ditemukan dan keberadaannya meliputi seluruh alam (mung dumunung mring kang awas, mung sasmita aneng ing jagad ngebeki). ${ }^{29}$

\section{Identitas Bisri Mustafa dan Tafsir al-Ibriz}

a. Biografi Bisri Mustafa

Bisri Mustafa dilahirkan pada tahun 1915 M., di kampung Sawahan Gg. Palen Rembang Jawa Tengah dari pasangan H. Zainal Mustofa dan

\footnotetext{
${ }^{26}$ Dumadi, Mikul Dhuwur Mendhem Jero: Menyelami Falsafah Dan Kosmologi Jawa, 34-35.

${ }^{27}$ Woodward, Islam Jawa: Kesalehan Normatif versus Kebatinan, 111-12.

${ }^{28}$ Sujamto, Sabda Pandita Ratu (Semarang: Dahara Press, 1993), 17.

29 Suwardi Endraswara, Agama Jawa: Ajaran, Amalan Dan Asal Usul Kejawen (Yogyakarta: Penerbit Narasi, 2018), 270.
} 
Chodijah. ${ }^{30}$ Bisri lahir dari keluarga yang berkecukupan. Ayahnya bekerja bekerja sebagai pedagang yang dikenal dengan Djojo Mustopo. Nama asli ayahnya adalah Djaja Rabitan, yang dikenal sebagai orang yang dermawan dan mencintai kiai. Ibunya adalah Chodijah yang masih memiliki keturunan Makassar. ${ }^{31}$ Bisri Mustafa lahir dengan nama Mashadi. Ia adalah anak pertama dari empat bersaudara, yakni Mashadi, Salamah (Aminah), Misbach, dan Ma'shum. Selain itu, Mashadi memiliki saudara dari hasil pernikahan ayah dan ibunya sebelumnya. Sebelum menikah dengan Chodijah, Zainal Mustofa menikah dengan Dakilah dan dikaruniai dua orang anak, H. Zuhdi dan H. Maskanah. Sedangkan Chodijah menikah dengan Dalimin dan dikaruniai dua orang anak, Achmad dan Tasmin. ${ }^{32}$

Pada tahun 1923, Mashadi diajak ayanya untuk ikut dalam rombongan Haji ke Makkah beserta saudara-saudaranya yang lain. Anggota keluarga yang ikut serta dalam perjalanan tersebut diantaranya, $\mathrm{H}$. Zainal Mustafa, Chodijah, Mashadi (8 tahun), Salamah (5,5 tahun), Misbach (3,5 tahun), dan Ma'shum (1 tahun). Rombongan ini menggunakan kapal Chasan Imazi Bombay dan naik dari pelabuhan Rembang. ${ }^{33}$ Setibanya di Makkah, Mashadi mengalami sakit, sehingga dalam menjalankan rukun haji, ia harus ditandu. Dalam perjalanan pulang ke Indonesia melalui Jaddah, H. Zainal Mustafa mengalami sakit keras dan wafat di usia 63 tahun. Jenazahnya diserahkan ke seorang Shekh untuk dimakamkan dengan pihak keluarga membayar sebesar 60 rupiah sebagai biaya pemakaman dan sewa tanah pemakaman, karena saat wafat, bersamaan dengan keberangkatan kapal, pihak keluarga tidak dapat mengantarkan jenazah, sehingga pihak keluarga tidak pernah tahu letak pemakaman $\mathrm{H}$. Zainal Mustafa. $^{34}$ Setibanya di Indonesia, Mashadi mengganti namanya dengan Bisri, dan selanjutnya ia dikenal dengan sebutan Bisri Mustafa.

Sejak peristiwa di Jeddah, Bisri Mustafa memasuki babak baru dalam kehidupannya. Sebelumnya, semasa ayahnya hidup, seluruh tanggung jawab keluarga menjadi tanggung jawab H. Zainal Mustafa.

\footnotetext{
30 Saifillah Ma'sum, Karisma Ulama: Kehidupan Ringkas 26 Tokoh NU (Bandung: Mizan, 1998), 319.

31 Ahmad Zainal Huda, Mutiara Pesantren: Perjalanan Khidmah KH. Bisri Mustafa (Yogyakarta: LKiS, 2005), 9.

${ }^{32}$ Huda, 8-9.

${ }^{33}$ Ma'sum, Karisma Ulama: Kehidupan Ringkas 26 Tokob NU, 320.

${ }^{34}$ Huda, Mutiara Pesantren: Perjalanan Khidmah KH. Bisri Mustafa, 9-10.
} 
Ketika ayahnya wafat, terjadi perubahan yang signifikan dalam kehidupan keluarga Bisri. Seluruh tanggung jawab keluarga, termasuk keperluan pendidikan Bisri, beralih ke $\mathrm{H}$. Zuhdi, saudara tirinya. Untuk menjamin masa depan Bisri Mustafa, H. Zuhdi memilihkan pendidikan yang layak untuk adiknya di Rembang. Pada masa itu, di Rembang terdapat tiga macam sekolah; pertama, Eropese School, sekolah khusus anak priyayi tinggi. Kedua, Hollands Inlands School (HIS), sekolah yang muridnya terdiri dari anak-anak pegawai negeri yang penghasilannya tetap. Ketiga, Sekolah Ongko Loro (sekolah Jawa), sekolah yang murid-muridnya terdiri dari anak kampung, pedagang, dan anak tukang. Bisri oleh kakaknya didaftarkan di HIS. $^{35}$

Bisri diterima masuk sekolah HIS, sebab ia diakui sebagai keluarga Raden Sudjono, mantri guru HIS yang bertempat tinggal di Sawahan Rembang yang merupakan tetangga keluarga Bisri. Setelah perihal ini diketahui oleh $\mathrm{KH}$. Cholil, pengasuh pesantren Kasingan, ia memberikan nasehat kepada $\mathrm{H}$. Zuhdi untuk membatalkan rencana tersebut. $\mathrm{KH}$. Cholil beranggapan bahwa HIS adalah sekolah milik penjajah Belanda yang dikhususkan bagi anak pegawai negeri yang berpenghasilan tetap, sedangkan Bisri hanya seorang anak pedagang. Ia juga beralasan bahwa tidak pantas mengaku sebagai keluarga orang lain hanya untuk bisa belajar di HIS. Faktor lain dari pelarangan KH. Cholil adalah kebenciannya terhadap Belanda. Ia khawatir Bisri nantinya memiliki watak seperti penjajah Belanda. Atas dasar itu, Bisri dipindah ke Sekolah Ongko Loro dan mendapatkan sertifikat setelah menempuh pendidikan selama tiga tahun. ${ }^{36}$

Sebelum sekolah di Sekolah Ongko Loro, Bisri Mustofa mengaji ke KH. Cholil Kasingan. Akan tetapi kegiatan ini berhenti seiring dengan masuknya Bisri di Sekolah Ongko Loro. Waktu yang bersamaan menjadi alasan Bisri berhenti mengaji di Pesantren Kasingan, sehingga untuk memenuhi pendidikan informal tersebut, Bisri mengaji pada kakaknya, $\mathrm{H}$. Zuhdi. Pada tahun 1925, Bisri bersama dengan Maskub (H. Muslich), diantar oleh kakaknya ke Pesantren Kajen untuk mengikuti kegiatan pondok pesantren selama bulan Ramadhan. Akan tetapi, setelah tiga hari mengikuti kegiatan tersebut, ia tidak kerasan dan kembali lagi ke Rembang. ${ }^{37}$ Setelah lulus dari Sekolah Ongko Loro, tahun 1926, Bisri diminta

\footnotetext{
${ }^{35}$ Ma'sum, Karisma Ulama: Kehidupan Ringkas 26 Tokoh NU, 321.

${ }^{36}$ Huda, Mutiara Pesantren: Perjalanan Kbidmah KH. Bisri Mustafa, 11.

${ }^{37}$ Huda, 12.
} 
H. Zuhdi untuk melanjutkan pendidikan di Pondok Pesantren Kasingan, yang diasuh Kiai Cholil. Ketidaktertarikan Bisri pada pendidikan tersebut menjadikan hasil yang dicapainya tidak memuaskan, sehingga tidak lama setelah itu, ia berhenti dan kembali ke Rembang.

Setelah beberapa bulan di Rembang, pada tahun 1930, ia diperintahkan kembali ke Kasingan, dan dipasrahkan kepada Suja'i yang merupakan ipar dari Kiai Cholil. Pada awal masa pendidikannya di Pesantren, ia tidak langsung mengaji kepada Kiai Cholil tetapi justru mengaji ke Suja'i, ipar Kiai Cholil. Hal ini lebih disebabkan oleh ketidaksiapan Bisri untuk mengaji langsung ke Kiai Cholil yang dikenal memiliki watak yang keras. Faktor lainnya adalah, Bisri ingin menyiapkan diri sebelum langsung mengaji ke Kiai Cholil dan membuktikan kepada teman-temannya yang tidak memberikan tanggapan baik ketika Bisri belajar pertama kali di Pesantren. ${ }^{38}$

Ketika Bisri mengaji ke Suja'i, ia hanya mempelajari kitab Alfiyah karya Ibn Ma>lik selama dua tahun, sehingga ia benar-benar menguasai kitab tersebut. Pada saat Kiai Cholil membuka pengajian Alfiyah, Bisri diperintahkan oleh Suja'i untuk ikut dalam pengajian tersebut dan diharuskan untuk duduk di paling depan. Tujuannya agar Bisri dapat lebih paham penjelasan Kiai Cholil dan dapat menjawab seluruh pertanyaan yang diberikan kiai Cholil. Tujuan tersebutpun tercapai, setiap ada pertanyaan dari Kiai, Bisri yang pertama kali menjawab, dan hal tersebut dapat memancing perhatian teman-temannya. Bisri mulai mendapatkan perhatian khusus dari teman-temannya dan mulai menjadikan Bisri tempat rujukan tentang permasalahan dalam Alfiyab. ${ }^{39}$ Satu tahun kemudian, ia mulai mempelajari kitab Fath\} al-Mu'in. Setelah selesai, baru ia mengaji kitab-kitab lainnya seperti, Fath\} al-Wabhab, Iqna', Jam'u al-Jawami', Uqud alJuman, dan kitab-kitab lainnya.

Sejak tahun 1933, Bisri Mustafa sudah dipandang sebagai seorang santri yang memiliki pemahaman terhadap kajian-kajian ke-Islaman yang mumpuni dan menjadi rujukan bagi santri lainnya. Pada tahun ini juga, adik Bisri menyusul untuk menempuh pendidikan di Kasingan, sehingga biaya yang dikeluarkan oleh kakaknya, H. Zuhdi bertambah. Untuk mengurangi beban kakaknya, Bisri mulai berjualan kitab yang ia ambil dari

\footnotetext{
${ }^{38}$ Ma'sum, Karisma Ulama: Kebidupan Ringkas 26 Tokob NU, 322.

${ }^{39}$ Huda, Mutiara Pesantren: Perjalanan Khidmah KH. Bisri Mustafa, 14.
} 
toko kakaknya. Keuntungan dari penjualan tersebut dijadikan tambahan untuk biaya di pesantren. ${ }^{40}$

Pada tahun 1932, Bisri meminta restu kepada KH. Cholil untuk melanjutkan pendidikannya di Pesantren Termas asuhan KH. Dimyati. Permintaan tersebut tidak direstui oleh KH. Cholil, bahkan ia cenderung melarang. KH. Cholil beralasan bahwa di Kasinganpun Bisri tidak akan menghabiskan seluruh ilmu yang diajarkan. Keinginan Bisri pidah ke Termas lebih disebabkan oleh mayoritas temannya melanjutkan pendidikan di Termas. Bisri tidak berani untuk melanggar apa yang telah dititahkan oleh gurunya, sehingga ia tidak melanjutkan niat untuk pindah ke Termas.

Pada bulan Sya'ban tahun 1934, KH. Cholil memerintahkan Bisri untuk mengikuti pengajian kitab Saib\} Bukhari dan Sabih Muslim yang diadakan oleh KH. Hasyim Asy'ari di Pondok Pesantren Tebuireng Jombang. Pengajian tersebut dimulai tanggal 21 Sya'ban, tetapi yang dibacakan adalah kitab Sabih Muslim dan Tajrid al-Bukhari. Pada 10 Ramadhan, KH. Hasyim Asy'ari jatuh sakit dan pengajiannya dilanjutkan oleh KH. Ilyas untuk melanjutkan pengajian Sabih Muslim dan KH. Baidhowi untuk melanjutkan kitab Tajrid al-Bukhari. ${ }^{41}$

Setelah Bisri dinikahkan dengan putri KH. Cholil, Ma'rufah pada tahun 1934, Bisri mulai mengajar di Pesantren Kasingan. Dengan adanya tanggung jawab tersebut, Bisri merasakan beban yang begitu berat, terlebih setelah wafatnya KH. Dimyati, banyak santri Termas yang notabenenya alumi Kasingan kembali lagi mondok di Kasingan. Kebanyakan mereka ingin mengaji ke Bisri dengan kitab yang belum pernah Bisri dalami sebelumnya. Untuk mengatasi prolem tersebut, sebelum mengajar Bisri mendiskusikan kitab yang akan dibacakan dengan Kiai Kamil dan Kiai Fadholi di Karanggeneng. Hasil musyawarah yang diperolehnya, diajarkan kepada santrinya, sehingga jadwal pengajaran santri bergantung pada jadwal musyawarahnya di Karanggeneng. Tidak betah dengan model semacam ini, keinginan Bisri untuk meningalkan Rembang dan menempuh pendidikan mulai muncul kembali.

Pada musim haji tahun 1936, Bisri mendapatkan restu dari KH. Cholil untuk menunaikan haji dari hasil tabungannya dan dari hasil penjualan kitab Hashiyah Bujairomi Iqna' karya KH. Cholil. Selama di

\footnotetext{
${ }^{40}$ Huda, 14.
}

${ }^{41}$ Huda, 15. 
Makkah, ia menumpang di rumah Shaykh Chamid Said sebagai khadam. Menjelang rombongan haji pulang, Bisri mulai mengingat kondisi pada saat ia mengajar, sehingga bersama dengan temannya, Suyuti Cholil dan Zuhdi dari Tuban, Bisri memutuskan untuk tinggal di Makkah untuk memperdalam ilmunya. Di Makkah ia menuntut ilmu kepada KH. Bakir, Shaykh Umar Chamdan al-Maghribi, Sheykh Maliki al-Hasani, Sayyid Amin, Sheykh Hasan Mashshat\}, Sayyid Alawiy, dan KH. Abdul Muhaimin. ${ }^{42} \mathrm{KH}$. Bisri Mustofa bermukim di Makkah selama satu tahun. Ia kemudian diminta pulang oleh KH. Cholil, dan pada tahun 1937, ia kembali ke Rembang bersama kedua temannya.

Hasil karya KH. Bisri Mustafa meliputi berbagai bidang keilmuan, diantaranya: Ilmu Tafsir dan Tafsir, Ilmu Hadis dan Hadis, ilmu Nahwu, ilmu S \}araf, Fikih, dan Akhlak. Jumlah keseluruhan dari karyanya berkisar 176 judul. Dalam penulisan karya-karya tersebut, KH. Bisri Mustafa menggunakan bahasa yang beragam, ada yang berbahasa jawa dengan penulisan penggunakan pegon, ada yang berbahasa Indonesia, dan juga ada yang menggunakan bahasa Arab. Karya-karyanya diantaranya: ${ }^{43}$ Tafsir alIbriø, Al-Ikthir, Terjemah Kitab Bulugh al-Maram, Terjemah Hadis 'Arba'in al-Nawawi, Islam dan Shalat, Islam dan Taubid, 'Aqidah Abl al-Sunnah wa alJama'ah, al-Baiquniyah, Terjemah Sharb\} Alfiyah Ibn Malik, Terjemah Sharh al-Jurumiyah, Terjemah Sharb Imriti, Terjemah Sullam al-Mu'awanah, Safinah al-Salat, Terjemah Kitab Faraid al-Babiyah, Muniyat al-Azman, Lataif alIrshad, Al-Nabras, Mansik Haji, Kashkul, al-Risalat al-Hasanat, al-Wasaya li alAba' wa Abna', Islam dan Keluarga Berencana, Kotbah Jum'at, Al-Ta'liqat alMufidah li al-Qasidah al-Munbarifat.

Karya-karya KH. Bisri Mustofa tersebut, pada umumnya ditujukan pada dua kelompok sasaran. Pertama, kelompok santri yang sedang belajar di Pesantren. Kedua, masyarakat umum di pedesaan yang giat dalam pengajian di surau dan langgar. Dalam hal ini karya-karya untuk mereka lebih banyak berupa ilmu-ilmu praktis yang berkaitan dengan soal ibadah. ${ }^{44}$ b. Tafsir al-Ibriz: Latar Belakang, Karekteristik dan Metode

Secara eksplisit, Bisri Mustafa tidak menjelaskan latar belakang penulisan tafsir al-Ibri\%. Latar belakang penulisan tafsir ini justru

\footnotetext{
${ }^{42}$ Ma'sum, Karisma Ulama: Kehidupan Ringkas 26 Tokob NU, 323.

${ }^{43}$ M. Ramli HS, Corak Pemikiran Kalam KH. Bisri Mustafa: Studi Komparatif Dengan Teologi Tradisional Asy'ariyah (Tesis: IAIN Syarif Hidayatullah, 1994), 19-20.

${ }^{44} \mathrm{Ma}$ 'sum, Karisma Ulama: Kehidupan Ringkas 26 Tokoh NU, 328.
} 
diungkapkan oleh Mustafa Bisri. Ia mengungkapkan bahwa tujuan penulisan tafsir ini adalah untuk memudahkan pemahaman terhadap kandungan al-Qur'an bagi masyarakat Jawa. ${ }^{45}$ Menurut Cholil Bisri, penulisan tafsir ini tidak bisa dilepaskan dari kegiatan pengajian rutin yang dilakukan oleh Bisri Mustafa setiap hari Selasa dan Jum'at. Cholil Bisri mengungkapkan,

Kegiatan menulis Bisri diawali dengan kegiatan memberi makna kitab kuning yang digunakan dalam pesantren. Dan karena dorongan teman-teman Bisri, maka kegiatan memberi makna itu ditingkat menjadi buku dan disebarkan ke pesantren-pesantren. Khusus ketika Bisri menulis tafsir al-Ibriz yang dianggap hasil karya yang paling besar, Bisri selalu dalam keadaan suci tidak berhadas dan disertai ibadah puasa sunnag hari senin dan kamis. Bisri menulis tafsir selama kurang lebih empat tahun, jadi kira-kira tahun 1957-1960. Setiap mendapat satu juz, Bisri mengajak murid-murid yang dekat pergi ziarah ke kuburan Wali Sembilan. ${ }^{46}$

Hal ini juga diperkuat oleh Mustafa Bisri, bahwa kitab tafsir ini ditulis untuk menjadi bahan bacaan bagi masyarakat yang memahami tulisan Arab-pegon (pesantren), dan menjadi pegangan bagi para guru di Pesantren. Ada perbedaan tahun dikarangnya kitab ini. Menurut Mustafa Bisri kitab ini mulai ditulis tahun $1369 \mathrm{H}$ atau $1951 \mathrm{M}$., dan selesai ditulis tanggal 29 Rajab $1379 \mathrm{H}$. atau 28 Januari 1960 M, , sedangkan menurut Cholil Bisri dimulai tahun 1957 dan selesai tahun 1960.

Secara sistematika penulisan, tafsir ini memiliki dua jenis cetakan. Pertama cetakan yang diterbitkan oleh Menara Kudus dengan berjumlah tiga puluh jilid yang menyesuaikan dengan jumlah Juz dalam al-Qur'an dengan format pegon. Meskipun demikian, struktur halaman pada setiap volume menyesuaikan dengan halaman terakhir dari volume sebelumnya tanpa dimulai dari awal. Misalnya pada volume. ketiga dimulai dengan nomor 100 karena akhir dari volume kedua pada nomor 99 dan seterusnya hingga akhir volume. Sedangkan pada jenis cetakan kedua, yang

\footnotetext{
${ }^{45}$ Mustofa, Al-Ibriz: Tafsir al-Qur'an Bahasa Jawa, vi.

${ }^{46}$ Iing Misbahuddin, “Tafsir Al-Ibri>z Li> Ma'rifah Tafsi >r al-Qur'an al-Azi>z Karya KH. Bisri Mustafa Rembang: Studi Metodologi Dan Pemikiran” (IAIN Sunan Kalijaga Yogyakarta, 1989), 98.

${ }^{47}$ Mustofa, Al-Ibriz: Tafsir al-Qur'an Bahasa Jawa, vi.
} 
merupakan edisi terbaru, dicetak oleh Lembaga Kajian Strategis Indonesia dengan format satu volume dengan menggunakan bahasa Jawa Latin.

Tafsir al-Ibriz, merupakan salah satu kitab tafsir di Indonesia yang lahir dalam lingkup budaya pemaknaan pesantren, yang penjelasan terhadap satu ibarat (teks) dilakukan dengan cara sharb ${ }^{48}$ dan pemberian bamish. ${ }^{49}$ Model penjelasan semacam ini mempengaruhi Bisri Mustafa dalam penulisan Tafsir al-Ibri\%. Struktur penulisan tafsir al-Ibriz, pada cetakan jenis pertama, dalam setiap halaman menggunakan dua metode tersebut, satu halaman memuat ayat-ayat al-Qur'an yang diletakkan dalam sebuah kolom disertai penjelasan makna kata dengan menggunakan teknik pegon $^{50}$ lengkap dengan kedudukan dan fungsi kata tersebut dalam satu kalimat sesuai dengan kajian ilmu Nahwu. Penjelasan kandungan setiap ayat ditulis di luar kotak, di pinggir halaman. Dalam memberikan penafsiran pada ayat, Bisri tidak memberikan penjelasan setiap ayat dalam satu surat, akan tetapi penjelasan tersebut kadangkala dilakukan dengan merujuk pada keterkaitan antar ayat. Jika suatu ayat memiliki keterkaitan dengan ayat berikutnya, maka penjelasan dari ayat tersebut dikumpulkan.

Dalam memberikan penjelasan (penafsiran), kadang kala Bisri menggunakan cara terjemah secara ma'nawiyah. Hal ini dilakukan pada ayat yang dinilai secara literlek dapat dipahami langsung mantuq dan tidak membutuhkan banyak penjelasan. Metode penafsiran yang ditempuh Bisripun dalam kasus ayat semacam ini memiliki perbedaan dengan gaya yang biasa digunakan dalam tafsir-tafsir pada umumnya yang terfokus pada struktur bahasa Arab. Dengan struktur semacam ini, tafsir al-Ibriz lebih dekat pada terjemahan dari pada tafsir, sehingga Martin van Bruinessen menggolongkan al-Ibriz sebagai terjemahan dari pada penafsiran alQur'an. ${ }^{51}$ Akan tetapi dalam beberapa ayat yang dianggap membutuhkan penjelasan yang lebih banyak, Bisri menjelaskannya dengan panjang dengan menyertakan tanbih, faidah, qissab dan mubimmah.

Ditinjau dari penggunaan bahasa, tafsir al-Ibriz menggunakan bahasa Jawa ngoko yang dicampur dengan bahasa Indonesia yang bertujuan

\footnotetext{
48 Penjelasan yang dilakukan secara langsung, mengikuti redaksi yang dijelaskan. Metode ini juga dilakukan dengan memberikan makna gantung pada lafad (kata) dalam satu redaksi.

${ }^{49}$ Penjelasan yang ditulis dengan cara memberikan catatan pinggir pada halaman redaksi yang dijelaskan.

${ }^{50}$ Sistem penulisan dengan menggunakan bahasa Jawa dengan aksara Arab.

${ }^{51}$ Martin van Bruinessen, Kitab Kuning, Pesantren Dan Tarekat: Tradisi-Tradisi Islam Di Indonesia (Bandung: Mizan, 1999), 144.
} 
agar lebih dekat dengan audiens. Hal inipun disampaikan oleh Mustafa Bisri dalam pengantar cetakan terbaru, bahwa tujuan dari tafsir ini ditulis agar dapat dimengerti oleh para pengkaji al-Qur'an yang mayoritas merupakan orang Jawa. Metode penyampaian dengan menggunakan campuran bahasa Indonesia, ditengarai karena adanya pengaruh dari penggunaan bahasa Jawa pada masa tersebut yang sudah banyak bercampur dengan bahasa Indonesia yang merupakan bahasa pemersatu bangsa.

Bisri juga memberi penekanan pada hirarki bahasa yang terdapat dalam tata bahasa Jawa. Tata bahasa Jawa mengenal tingkatan bahasa yang berbeda yang disesuaikan dengan tingkatan lawan bicaranya atau subjek yang hendak dituju. ${ }^{52} \mathrm{Hal}$ ini berbeda dengan tata bahasa Arab yang hanya membedakan kosa katanya berdasarkan jenis kelamin. Kondisi semacam ini memberikan pengaruh yang signifikan terhadap Bisri dalam penggunaan bahasa yang disandarkan pada hal yang dianggap memiliki kemuliaan, misalnya menambahkan kata gusti pada lafaz\} Jala $>$ lah, penyebutan kanjeng ketika menyebut Nabi, ngersane sebelum perkara yang diagungkan dan kata dewi atau siti pada nama-nama perempuan yang disebut dalam ayat-ayat kisah.

Sedangkan untuk menentukan metode penafsiran dalam tafsir alIbri $>$ z, perlu diklasifikasikan terlebih dahulu beberapa pendapat mengenai metode tafsir. Al-Farma $>$ wi $>$ membagi metode penafsiran menjadi empat macam. Pertama, metode tafsir ijma $>l i>$, yakni metode menafsirkan alQur'an hanya dengan menjelaskan kata-kata yang dianggap penting untuk dijelaskan. Metode ini juga disebut sebagai metode tafsir global, karena hanya menjelaskan kandungan ayat secara umum. kedua, metode tafsir tab\} $\mid i>l i>$, yakni cara menafsirkan al-Qur'an dengan menjelaskan keseluruhan aspek, baik dalam segi bahasa, susunan kalimat, munasabah, $a s b a>b$ al-nu₹u>l, kandungan hukum dan hal lainnya secara terperinci. Ketiga, metode tafsir muqa $>$ ran, yakni cara penjelasan kandungan ayat-ayat al-Qur'an dengan membandingkan satu pendat dengan pendapat yang lainnya. Keempat, metode tafsir mawd $\} u>i>$, yakni penjelasan makna dan kandungan ayat yang memiliki satu tema tertentu. ${ }^{53}$ Berdasarkan pemetaan tersebut, tafsir al-Ibriz termasuk dalam tafsir dengan metode ijma $>l i>$,

${ }^{52}$ Geertz, Keluarga Jawa, 19.

53 Abd al-Hayy Al-Farmawi, Metode Tafsir Maudhu'i Dan Cara Penerapannya, trans. Rosihon Anwar (Bandung: Pustaka Setia, 2002), 38-39. 
karena dalam menafsirkan ayat-ayat al-Qur'an, Bisri tidak melakukan penjelasan secara terperinci atas kandungan lafad dalam ayat.

Sedangkan Ridlwan Nasir membagi metode tafsir menjadi empat. Pertama, ditinjau dari sumber penafsirannya; kedua, ditinjau dari cara penjelasannya; ketiga, ditinjau dari keluasan penjelasan; keempat, ditinjau dari sasaran dan tertib ayat yang dijelaskan. Metode tafsir ditinjau dari sumber penafsirannya, dibagi menjadi tiga, metode tafsir bi al-ma'thur, bi alra'yi dan bi al-iqtirani. Sedangkan metode tafsir ditinjau dari cara penjelasannya, Ridlwan Nasir membaginya menjadi dua macam, metode bayani dan metode muqarin. Sedangkan metode tafsir ditinjau dari keluasan penjelasan, Ridlwan Nasir membaginya menjadi dua, metode tafsir ijmali dan itnabi. Metode tafsir ditinjau dari sasaran dan tertib ayat, dibagi menjadi tiga, metode tafsir tabliliy, mawdu' dan nuzuli..$^{54}$

Jika pembagian metode tafsir ini didasarkan pada pembagian yang dilakukan Ridlwan Nasir, maka didasarkan pada sumber penafsirannya, tafsir al-Ibriz tergolong tafsir dengan metode bi al-ra'y, meskipun dalam beberapa hal, Bisri Mustafa mencantumkan riwayat terutama saat penyebutan asbab al-nuzul. Pengkatagorian tafsir ini dalam metode bi al-ra'y dari pada bi al-iqtiran didasarkan pada cara yang ditempuh Bisri tidak sesuai dengan apa yang dimaksud Abdul Jalal dalam kategori tafsir bi al-iqtiran. Dalam terminologinya, tafsir bi al-iqtira $>n$ menuntut penafsir menguraikan makna ayat al-Qur'an dengan mengkomparasikan riwayat-riwayat kuat dengan dalil-dalil aqli (argumentatif), sedangkan dalam al-Ibriz penyebutan riwayat hanya memiliki porsi yang sedikit, yang hanya disebutkan sebagai penguat ijtihad dari Bisri.

Sedangkan didasarkan pada cara penjelasannya, tafsir ini dapat dikategorikan sebagai tafsir bayani dengan menonjolkan penjelasan secara mandiri terhadap sebuah ayat tanpa adanya pembandingan dengan ayat lain, dengan hadis ataupun pendapat para mufassir sebelumnya. Sedangkan jika ditinjau dari keluasan penjelasan, tafsir ini masuk dalam kategori ijmali, dan jika didasarkan pada susunan penafsiran, tafsir al-Ibriz masuk dalam kategori tafsir tablili dengan penafsirannya yang dimulai dari al-Fatihah hingga al-Nas sesuai dengan tertib mushafi.

\footnotetext{
${ }^{54}$ Ridlwan Nasir, Memahami Al-Qur'an: Perspektif Baru Metodologi Tafsir Muqarin (Surabaya: CV. Indra Media, 2003), 13-17.
} 


\section{Kesatuan Kosmis dalam Tafsir al-Ibriz: Relasi Makrokosmos dan Mikrokosmos}

Konsepsi kosmologis dalam pandangan Jawa selalu memisahkan alam dengan kategeri-kategori khusus. Mereka menyebut alam nyata (dunia) sebagai jagat cilik, sedangkan jagat raya disebut dengan jagat gede. Keduanya memiliki hubungan yang tidak terpisahkan dan mempengaruhi satu dengan yang lain. Hubungan antara keduanya merupakan problem utama dalam setiap pembahasan kosmologi Jawa. Hubungan ini juga merepresentasikan kebutuhan manusia Jawa terhadap ketentraman dan keserasian, karena di dalam hubungan ini mempengaruhi seluruh konsepsi hidup. Dalam konteks ini, Magnis-Suseno menyebutkan bahwa perilaku sosial mansyarakat Jawa hampir tidak dapat dibedakan dengan perilaku keagamaannya, karena konsep kemanunggalan dalam kosmologi yang mereka anut. ${ }^{55}$

Keyakinan utama dalam pandangan Jawa adalah kesatuan eksistensi antara makrokosmos dengan mikrokosmos. ${ }^{56}$ Kesatuan eksistensi ini dalam pandangan Jawa dikenal dengan kesatuan numinus yang meliputi alam nyata, manusia dan alam kodrati. Setiap peristiwa yang terjadi dalam dunia nyata, merepresentasikan kekuatan-kekuatan adikrodati sebagai tempat manusia mengantungkan kehidupannya. ${ }^{57}$ Konsep ini juga mewarnai beberapa pemahaman Bisri Mustafa dalam tafsir al-Ibriæ. Meskipun, Bisri memberikan beberapa istilah yang lebih Islami dalam menjelaskan pandangan mengenai kesatuan numinus tersebut.

Pengertian yang menyamai mikromosmos dalam pandangan Jawa dengan penjelasan Bisri dalam al-Ibriz memiliki kesamaan dengan mengartikannya sebagai dunia nyata. Dunia yang dimaksud adalah dunia yang ditempati manusia dengan segala potensinya. Manusia memiliki kuasa atas segala kemanfaatan yang terkandung di dunia. ${ }^{58} \mathrm{Hal}$ ini mengindikasi bahwa dunia (mikrokosmos) dalam pandangan Bisri berpusat pada manusia.

Sebagai pusat dari mikrokosmos, manusia dituntut untuk selalu mengingat dan mengesakan Tuhan. Hubungan ini sebagai implikasi dari ketersediaan kebutuhan yang diinginkan manusia oleh Allah sebagai penciptanya. Implementasi dari tuntunan ini dijabarkan oleh Bisri dalam konsep amal. Amal yang dimasud adalah amal ibadah yang dikhususkan kepada

\footnotetext{
${ }^{55}$ Magnis-Suseno, Etika Jawa: Sebuah Analisis Falsafati Tentang Kebijaksanaan Hidup Jawa, 117.

${ }^{56}$ Neil Mulder, Pribadi Dan Masyarakat Jawa (Jakarta: Pustaka Sinar Harapan, 1996), 19.

${ }^{57}$ Magnis-Suseno, Etika Jawa: Sebuah Analisis Falsafati Tentang Kebijaksanaan Hidup Jawa, 83-86.

${ }^{58}$ Mustofa, Al-Ibri>z: Tafsir al-Qur'an Bahasa Jawa, 4.
} 
Allah dan amal yang berkaitan dengan manusia dalam kehidupan sosialnya. Amal-amal yang berhubungan dengan Allah adalah kewajiban menjalankan syariah dan istiqomah dalam menjalankannya. ${ }^{59}$ Hal lain yang juga menjadi tuntutan manusia di dunia adalah melakukan perbuatan baik kepada sesamanya. Bisri menjelaskan persoalan ini dalam kaitannya dengan penafsiran atas Q.S. alMaidah (5): 2, yakni Sira kabeh supaya padha tulung-tinulung ingatase ngalakoni kebagusan lan taqwa. Lan sira kabeh aja padha tulung-tinulung ingatase nglakoni dosa lan nganiaya (agar kalian selalu tolong menolong dalam kebaikan dan ketakwaan. Dan janganlah kalian saling tolong-menolong dalam perbuatan dosa dan aniaya). ${ }^{60}$

Kesatuan tindakan dan keyakinan keagamaan dalam konsep kosmologi Jawa, juga tergambar dalam beberapa penafsiran Bisri. Bisri menganggambarkan dunia nyata sebagai salah satu wujud kekuatan adikodrati yang menggerakkannya. ${ }^{61}$ Oleh sebab itu, segala hal yang terjadi di dunia, memiliki kaitan dengan susunan kosmos. Dunia dipandang hanya sebagai saran untuk mencapai dunia yang lebih hakiki dan kekal. Bisri mengistilahkan dunia sebagai dolanan (main-main) dan lelabanan (senda gurau), sedangkan dunia yang metaempiris dianggap sebagai dunia yang sesungguhnya yang menyuguhkan segala nikmat yang diinginkan oleh manusia. ${ }^{62} \mathrm{Hal}$ ini juga dapat dikatakan bahwa kecenderungan Bisri dalam melihat setiap tindakan manusia di dunia nyata, bukanlah ditujukan sebagaimana yang tampak dalam tindakan tersebut, akan tetapi merupakan tindakan yang mewakili keinginan manusia untuk mencapai dunia yang metapisis yang menjadi tujuan utama.

Kesatuan tindakan manusia di dunia dengan kehidupan di dunia akhirat menjadi indikasi keyakinan Bisri terhadap relasi mikrokosmos dengan makrokosmos. Kesatuan antar dua alam ini dijembatani oleh aturan-aturan yang ada diluar manusia yang tidak bisa dihindari olehnya. Konsep aturan ini dalam pandangan Jawa disebut sebagai panesti. ${ }^{63}$ Dengan konsep ini, manusia diwajibkan untuk tundak dan taat atas ketentuan-ketentuan yang terjadi di dunia nyata tanpa harus mempertanyakannya. Bisri memeberikan keyakinan atas konsep ini dalam penafsrinnya terhadap Q.S. al-Talaq (65): 3. Ia

\footnotetext{
${ }^{59}$ Mustofa, 513.

${ }^{60}$ Mustofa, 106.

${ }^{61}$ Mustofa, 75.

${ }^{62}$ Mustofa, 131.

${ }^{63}$ Soemarsaid Moetono, Negara Dan Usaha Bina-Negara Di Jawa Masa Lampau (Jakarta: Yayasan Obor Indonesia, 1985), 19.
} 
menjelaskan bahwa Allah memberikan rezeki kepada manusia dari jalan yang tidak pernah ia sangka sebelumnya, maka bagi orang yang menerima terhadap ketentuan-ketentuan tersebut, Allah akan mencukupi segala kebutuhannya. ${ }^{64}$

Mulder memberikan penjelasan mengenai konsep panesti yang diyakini oleh masyarakat Jawa. Menurutnya, konsep ini merupakan gambaran keyakinan Jawa terhadap konsep manunggaling. Mereka meyakini kejadian yang ada di dunia nyata merupakan gerak yang telah diatur oleh kekuatan adikodrati diluar dunia nyata tersebut. Kekuatan tersebut terintegrasi dalam setiap gerak mikorkosmos. Manusia sebagai bagian dari mikrokosmos tersebut harus menerima dan menjalankan sesuai dengan kepastian yang ditetapkan agar tidak menggangu keseimbangan dan keserasian dalam kosmos. ${ }^{65}$ Begitu juga dalam pandangan Bisri, ketentuan yang telah ditetapkan oleh Allah sebagai penguasa kosmos, harus dijalankan secara penuh agar tidak mendapatkan kemurkaan, dan menjadi penyebab dari segala kerusakan dan siksaan di alam akhirat.

\section{Simpulan}

Melalui penelitian ini dapat disimpulkan bahwa:

1. Konsep kosmologi menurut Bisri Mustafa dalam tafsir al-Ibriz tidak memiliki perbedaan yang signifikan dengan pandangan kosmologi Jawa pada umamnya. Kosmologi yang dipandangan sebagai kesatuan antara mikrokosmos dan makrokosmos, juga diyakini oleh Bisri. Bisri menganggap bahwa dunia nyata adalah arena yang digunakan manusia untuk mencapai dunia yang sesungguhnya, yakni akhirat. Dunia nyata tersebut, diangap berpusat pada manusia dalam hal pengelolaan dan pemanfaatannya. Akan tetapi, manusia sebagai pusat dari dunia nyata, memiliki kewajiban kepada Tuhan untuk tidak menyekutukannya. Meskipun demikian, konsep-konsep ke-Islaman dalam pandangan ini masih relitif mendominasi. Hal ini disebabkan karena disamping budaya Jawa yang melingkupi pemikiran Bisri, ia juga dipengaruhi tradisi pesantren yang lebih menonjolkan nuansa ke-Islaman.

2. Kecenderungan Bisri terhadap konsep-konsep pesantren, memberikan warna baru dalam pembahasan kosmologi Jawa. Mistisisme dan kekuatan adikodrati yang dijelaskan dalam konsep ini, teridentifikasi

\footnotetext{
${ }^{64}$ Mustofa, Al-Ibri>q: Tafsir al-Qur'an Bahasa Jawa, 566.

${ }^{65}$ Mulder, Pribadi Dan Masyarakat Jawa, 19.
} 
secara teologis, sehingga kerancuan atas pemahaman kosmologi dalam diarahkan pada pemahaman yang lebih religius. Meskipun demikian, konsep-konsep yang ditawarakan dalam penelitian ini membutuhkan banyak kajian lanjutan. Hal ini didasarkan pada ketumpang-tindahan kosmologi Jawa dengan konsep-konsep tasawuf dalam Islam.

\section{Daftar Pustaka}

Al-Farmawi, Abd al-Hayy. Metode Tafsir Maudhu'i Dan Cara Penerapannya. Translated by Rosihon Anwar. Bandung: Pustaka Setia, 2002.

Al-Rumi, Fu'ad Abd al-Rahman. Ittijahat Al-Tafsir Fi al-Qarn al-Rabi' 'Ashr. Vol. 1. Riyad: Mu'assasah al-Risalah, 1997.

Al-Zarkasyi, Muhammad bin Abd Allah. Al-Burhan Fi 'Ulum al-Qur'an. Vol. 2. Beirut: Dar Ihya' al-Kutub al-'Arabiyah, 1957.

Anderson, Benedic B. Mitologi Dan Toleransi Orang Jawa. Translated by Revianto B. Santoso and Luthfi Wulandari. Yogyakarta: Qalam, 2000.

Antognazza, Maria R. "Arguments for The Existence of God: The Continental European Debate." In The Cambridge History of Eighteenth-Century, edited by Knud Haakonssen, Vol. 1. New York: Cambridge University Press, 2006.

Asif, Muhammad. "Qur'anic Exegesis and The Tradition of The Pesantren: Characteristics of Tafsir al-Ibriz of Bisri Mustafa." SUHUF Jurnal Pengkajian Al-Qur'an Dan Budaya 9, no. 2 (2016): 241-64. https://doi.org/10.22548/SHF.V9I2.154.

Bahm, Archie J. Metaphysics: An Introduction. New Mexico: Harper \& Row, 1986. Bekker, Anton. Kosmologi Dan Ekologi: Filsafat Tentang Kosmos Sebagai Rumah Tangga Manusia. Yogyakarta: Kanisius, 1995.

Bruinessen, Martin van. Kitab Kuning, Pesantren Dan Tarekat: Tradisi-Tradisi Islam Di Indonesia. Bandung: Mizan, 1999.

Denys Lombard. Nusa Jawa: Silang Budaya. Jakarta: Gramedia Pustaka Utama, 2005.

Dumadi, Janmo. Mikul Dhunur Mendhem Jero: Menyelami Falsafah Dan Kosmologi Jawa. Yogyakarta: Shaida, 2011.

Endraswara, Suwardi. Agama Jawa: Ajaran, Amalan Dan Asal Usul Kejawen. Yogyakarta: Penerbit Narasi, 2018.

Gadamer, Hans-Georg. Truth and Method. Translated by Joel Weinsheimer and Donald G. Marshall. London: Continuum, 2006.

Geertz, Hildred. Keluarga Jawa. Jakarta: Grafiti Press, 1961. 
Hamid, Idrus al. "Eksistensi Kebudayaan Jawa Dalam Penafsiran KH. Bisri Mustafa." Mutawatir: Jurnal Keilmuan Tafsir Hadith 9, no. 1 (2019).

Huda, Ahmad Zainal. Mutiara Pesantren: Perjalanan Kbidmah KH. Bisri Mustafa. Yogyakarta: LKiS, 2005.

Janmo Dumadi. Mikul Dhuwur Mendhem Jero: Menyelami Falsafah Dan Kosmologi Jawa. Yogyakarta: Shaida, 2011.

Laksono, P. M. Tradisi Dalam Struktur Masyarakat Jawa Kerajaan Dan Pedesaan: Alih Ubah Model Berpikir Jawa. Yogyakarta: KEPEL Press, 2009.

Lombard, Denys. Nusa Jawa: Silang Budaya. Translated by Winarsih Partaningrat Arifin and Rahayu S. Hidayat. Jakarta: Gramedia Pustaka Utama, 2005.

Magnis-Suseno, Franz. Etika Jawa: Sebuah Analisis Falsafati Tentang Kebijaksanaan Hidup Jawa. Jakarta: Gramedia, 1984.

Ma'sum, Saifillah. Karisma Ulama: Kehidupan Ringkas 26 Tokoh NU. Bandung: Mizan, 1998.

Misbahuddin, Iing. "Tafsir Al-Ibriz Li Ma'rifah Tafsir al-Qur'an al-Aziz Karya KH. Bisri Mustafa Rembang: Studi Metodologi Dan Pemikiran.” IAIN Sunan Kalijaga Yogyakarta, 1989.

Moetono, Soemarsaid. Negara Dan Usaha Bina-Negara Di Jawa Masa Lampau. Jakarta: Yayasan Obor Indonesia, 1985.

Mulder, Neil. Pribadi Dan Masyarakat Jawa. Jakarta: Pustaka Sinar Harapan, 1996.

Mustofa, Bisri. Al-Ibriæ: Tafsir al-Qur'an Bahasa Jawa. Wonosobo: Lembaga Kajian Strategis Indonesia, 2015.

Nasir, Ridlwan. Memahami Al-Qur'an: Perspektif Baru Metodologi Tafsir Muqarin. Surabaya: CV. Indra Media, 2003.

Peursen, Cornelis A. Van. Strategi Kebudayaan. Yogyakarta: Kanisius, 1988.

Pratama, Aunillah Reza. "HAK-HAK PEREMPUAN DALAM TAFSIR ALIBRĪZ DAN TAFSIR TĀJ AL-MUSLIMĪN." SUHUF Jurnal Pengkajian Al-Qur'an Dan Budaya 11, no. 2 (December 31, 2018): 283308. https://doi.org/10.22548/SHF.V11I2.359.

Ramli HS, M. Corak Pemikiran Kalam KH. Bisri Mustafa: Studi Komparatif Dengan Teologi Tradisional Asy'ariyah. Tesis: IAIN Syarif Hidayatullah, 1994.

Sujamto. Sabda Pandita Ratu. Semarang: Dahara Press, 1993.

Woodward, Mark R. Islam Jawa: Kesalehan Normatif versus Kebatinan. Translated by Hairus Salim. Yogyakarta: LKiS, 2004.

Zayd, Nasr Hamid Abu. Tekstualitas Al-Qur'an: Kritik Terhadap Ulumul Qur'an. Translated by Khoiron Nahdliyyin. Yogyakarta: LKiS, 2013. 